\title{
Bilecik İli Hayvansal Atıklarının Biyogaz Potansiyelinin İncelenmesi
}

\section{Investigation of Biogas Potential of Animal Wastes in Bilecik}

\author{
Süheyla YEREL KANDEMIR ${ }^{1 *}$, Emin AÇIKKALP ${ }^{2}$
}

Geliş / Received: 20/05/2019

Revize / Revised: 21/06/2019

Kabul / Accepted: 24/06/2019

$\ddot{O}$

z- Ülkemizde kaynak bakımından önemli yenilenebilir enerji kaynaklarından bir tanesi de biyogazdır. Bilecik ili hayvancılığın yaygın olarak yapıldığı illerden bir tanesidir. Bu çalışmada ilk olarak, Bilecik ilindeki hayvanlarının sayısı ve atıklarının 2011- 2017 yılları arasındaki değişimi tespit edilmiştir. Bu veriler göz önüne alınarak hayvansal atıklardan elde edilebilecek biyogaz ve biyogazdan üretilebilecek elektrik enerjisi eşdeğeri belirlenmiştir. Bilecik'in 2011 yılında 1,017,522 tane ile en az hayvan sayısına sahip olduğu yıl, 2017'nin ise 4,609,707 tane ile en fazla hayvan sayısına sahip yıl olduğu görülmüştür. Veriler analiz edildiğinde, Bilecik ilinin 2017 yılında en fazla biyogaz potansiyeli ve en fazla elektrik enerjisi eşdeğerine sahip olduğu görülmüştür. Daha sonra yıllık elektrik enerjisi eşdeğerleri yılık elektrik tüketimi değerleri ile karşılaştırılmıştır. Sonuç olarak biyogazdan elde edilen yıllık elektrik enerjisi eşdeğerlerinin Bilecik ilindeki toplam yıllık elektrik tüketimini karşıladığı görülmüştür.

Anahtar Kelimeler- Biyogaz, Yenilenebilir Enerji, Hayvansal Atık, Bilecik

$A$

bstract- One of the important renewable energy sources in our country is biogas. Bilecik is one of the provinces where animal husbandry is widespread. In this study, firstly the number of animals in Bilecik province and the change of their wastes between 2011- 2017 were determined. Based on these data, biogas obtained from animal wastes and electrical energy equivalent produced from biogas were determined. Bilecik had the least number of animals in 2011 with 1,017,522 and 2017 had the highest number of animals with 4,609,707. When the data is analyzed, it is seen that Bilecik has the highest biogas potential and the highest electrical energy equivalent in 2017. Then, annual electrical energy equivalents are compared with annual consumed electrical energy values. As a result, it is seen that the annual electrical energy equivalents obtained from biogas meet the total annual electricity consumption in Bilecik.

Keywords- Biogas, Renewable Energy, Animal Waste, Bilecik

$$
\text { I. GİRIŞ }
$$

Dünya nüfusunun artması ve buna bağlı olarak sanayinin gelişmesi enerji kaynaklarına olan talebi artırmıştır. Ancak günümüzdeki enerji üretiminin bu enerji talebini sağlayamamasından dolayı enerji fiyatları gittikçe artmaktadır. Bu da enerjinin gittikçe daha pahalı olması anlamına gelmektedir [1-2].

Dünya nüfusu, küresel ısınmayla mücadele, enerji açığını kapatmak ve çevre sorunlarının çözümü için yeni ve yenilenebilir enerji kaynaklarına ihtiyaç duymaktadır. Günümüzde tüm ülkeler bu sorunların en aza indirgenmesi için çalışmalar yapmakta ve yenilenebilir enerji kaynaklarına yönelmektedirler [3].

Yenilenebilir enerji kaynakları içerisindeki enerji kaynaklarından biri de biyokütledir. Biyokütle ürünlerinden bir tanesi biyogazdır. Çevresel ve sağlık sorunları meydana getiren organik atıkların belirli işlemlerden geçerek zararsız hale getirilmesi ve enerjiye dönüştürülmesini sağlayan biyogaz teknolojisi yenilenebilir enerji sektöründe önemli bir yere sahiptir [4].

1*Sorumlu yazar iletișim: suheyla.yerel@bilecik.edu.tr (https://orcid.org/0000-0001-5356-1467)

Endüstri Mühendisliği Bölümü, Bilecik Şeyh Edebali Üniv, Gülümbe Kampüsü, Merkez, Bilecik

2Illetişim: emin.acikkalp@bilecik.edu.tr (https://orcid.org/0000-0003-4056-5383)

Makine Mühendisliği Bölümü, Bilecik Şeyh Edebali Üniv, Gülümbe Kampüsü, Merkez, Bilecik 
Araştırmalar biyogaz üretiminin, M.Ö. 10. yüzyılda Asurlulara ve M.S. 16. yüzyılda İranlılar’a kadar geri gittiğini bildirmektedir. Günümüzde ise, biyogaz üretimi tarımsal atıklar, hayvansal atıklar gibi organik atıkları yok etmek amacıyla yaygın olarak kullanılmaktadır [5-6].

Bu çalışmada, 2011-2017 yılları arasındaki Bilecik iline ait hayvansal kaynaklı atıklardan elde edilebilecek biyogaz potansiyelleri ve elektrik enerjisi eşdeğerleri incelenmiştir. Daha sonra elektrik enerjisi eşdeğerleri Bilecik ilindeki yıllık elektrik tüketim miktarları ile karşılaştırılmıştır.

\section{BIYYGAZ KAYNAKLARI VE ÖZELLİKLERİ}

Biyogaz üretimi için kullanılan malzemeler, hayvansal atıklar, bitkisel atıklar ve endüstriyel atıklar olmak üzere üç başlık altında incelenebilir [7]. Bunlar; hayvansal atıklar (hayvancılık yapılarak elde edilen atıklar ve hayvan gübreleri), bitkisel atıklar (bahçe ve yemek atıkları) ve endüstriyel atıklardır (zirai faaliyetler sonucu oluşan atıklar, orman ve kağıt endüstrisinden meydana gelen atıklar, deri ve tekstil endüstrisinden oluşan atıklar, gıda ve yağ endüstrisinden elde edilen atıklar, evsel katı atıklar, atık su arıtma tesisi atıkları).

Biyogaz üretiminin birçok amacı olmakla birlikte bunlardan bazıları aşağıda verilmiştir. Bunlar; enerji elde edilmesi, patojen giderimi sağlaması, toprak şartlandırıcının korozif etkisinin azalmasını sağlaması, atmosferdeki metan ve amonyak miktarının azaltılmasını sağlaması, organik maddelerin değerlendirilmesini ve dezenfeksiyonunu sağlaması olarak verilmektedir [8-10].

Hayvanlardan elde edilen gübre miktarları hayvanların cinsine göre değişmektedir. Hayvan atıklarından elde edilen biyogazın potansiyelinin belirlenmesi için çeşitli yöntemler mevcuttur. Bu çalışmada, biyogaz potansiyelini belirlemek için Akbulut ve ark. [11] ve Akdeniz [12]'deki yöntemler kullanılmıştır. Bu çalışmalara bağlı olarak, 1 adet büyükbaş hayvandan $35 \mathrm{~kg} /$ gün, 1 adet küçükbaş hayvandan $2 \mathrm{~kg} /$ gün ve 1 adet kanatlı hayvandan $0.16 \mathrm{~kg} /$ gün yaş gübre elde edildiği kabul edilmiştir. Biyogazın elektrik enerjisi olarak eşdeğerinin belirlenmesi için $1 \mathrm{~m}^{3}$ biyogazın elektrik enerjisi cinsinden değeri kullanılmaktadır. $1 \mathrm{~m}^{3}$ biyogaz $4.70 \mathrm{kWh}$ elektrik enerjisine eşdeğerdir $[6,13]$.

\section{BİLECİK İLİ BİYOGAZ POTANSIYYELİ}

Bilecik ilindeki 2011-2017 yıllarındaki büyükbaş, küçükbaş ve kanatlı hayvan sayıları Tablo 1'de verilmiştir. Çalışmada kullanılan 2011-2017 yıllarına ait veriler Türkiye İstatistik Kurumu resmi web sitesinden alınmıştır [14]. Tablo 1'e göre Bilecik iline ait belirlenen yıllar içerisinde en fazla toplam hayvan sayısı 4609707 ile 2017 yılındayken an az hayvan sayısı 1017522 ile 2011 yılında olduğu belirlenmiştir. İncelenen tüm yıllarda kümes hayvanı sayılarının diğer büyük ve küçükbaş hayvan sayılarına göre daha yüksek olduğu görülmektedir.

Tablo 1. Bilecik ilinin büyükbaş, küçükbaş ve kanatlı hayvanlarının sayısı (adet)

\begin{tabular}{|c|c|c|c|c|c|c|c|}
\hline $\begin{array}{l}\text { HAYVAN } \\
\text { GRUPLARI }\end{array}$ & $\mathbf{2 0 1 1}$ & $\mathbf{2 0 1 2}$ & $\mathbf{2 0 1 3}$ & $\mathbf{2 0 1 4}$ & $\mathbf{2 0 1 5}$ & $\mathbf{2 0 1 6}$ & $\mathbf{2 0 1 7}$ \\
\hline Büyükbaş & 40,358 & 41,956 & 42,240 & 40,181 & 39,198 & 32,499 & 36,071 \\
\hline Küçükbaş & 107,449 & 117,350 & 120,280 & 136,363 & 117,520 & 126,810 & 140,137 \\
\hline $\begin{array}{c}\text { Kümes } \\
\text { hayvanları }\end{array}$ & 869,715 & $1,108,221$ & $1,249,082$ & $1,254,876$ & $1,796,283$ & $2,179,332$ & $4,433,499$ \\
\hline $\begin{array}{c}\text { Genel toplam } \\
\mathbf{1 , 0 1 7 , 5 2 2}\end{array}$ & $\mathbf{1 , 2 6 7 , 5 2 7}$ & $\mathbf{1 , 4 1 1 , 6 0 2}$ & $\mathbf{1 , 4 3 1 , 4 2 0}$ & $\mathbf{1 , 9 5 3 , 0 0 1}$ & $\mathbf{2 , 3 3 8 , 6 4 1}$ & $\mathbf{4 , 6 0 9 , 7 0 7}$ \\
\hline
\end{tabular}

Bilecik ilindeki 2011- 2017 yılları arasındaki hayvan mevcuduna (büyükbaş, küçükbaş ve kanatlı) bağlı olarak toplam hayvan verileri yıllara göre analiz edilmiş ve biyogaz potansiyeli hesaplanmıştır. Daha sonra biyogaz potansiyeline ait hesaplama sonuçları Tablo 2'de sunulmuştur. Tablo incelendiğinde; büyükbaş, küçükbaş ve kanatlı hayvan miktarına ait gübre miktarı kullanılarak biyogaz üretilecek olursa en yüksek potansiyele sahip olan y1l 2017 olarak belirlenmiştir.

Bilecik ilinde yaşayan büyükbaş, küçükbaş ve kanatlı hayvanların, atıklarından üretilebilecek biyogaz potansiyelini belirlemek için yapılan bu çalışma göstermiştir ki son yıllarda il genelinde kanatlı hayvan sayısında ciddi bir artış meydana gelmiştir. Bilecik ilinin son yıllardaki kanatlı hayvan sayısındaki artışa bağlı olarak, 
hayvan atıkları bakımından önemli bir biyogaz potansiyeline sahip olduğu görülmektedir. Tablo 2 incelendiğinde kanatlı hayvan gübrelerinden üretilebilecek biyogazın en fazla 2017 yılında ve 30,381,761 $\mathrm{m}^{3} / \mathrm{y}_{1} \mathrm{olduğu}$ görülmektedir.

Tablo 2. Bilecik ilinde hayvansal atıklardan elde edilebilecek biyogaz potansiyeli

\begin{tabular}{|c|c|c|c|c|c|}
\hline Yil & Hayvan Cinsi & Hayvan Sayısı & $\begin{array}{c}\begin{array}{c}\text { Gübre miktarı } \\
\text { (ton/yıl) }\end{array} \\
\end{array}$ & $\begin{array}{c}\begin{array}{c}\text { Yıllık biyogaz miktarı } \\
(\mathrm{m} 3 / \mathrm{yl})\end{array} \\
\end{array}$ & $\begin{array}{c}\text { Yıllık üretilen biyogaz } \\
(\mathrm{m} 3 / \mathrm{yl})\end{array}$ \\
\hline \multirow[b]{3}{*}{2011} & Büyükbaş & 40,358 & 515,574 & $1,4972,253$ & $17,966,704$ \\
\hline & Küçükbaş & 107,449 & 78,438 & $8,471,279$ & $10,165,535$ \\
\hline & Kanatlı & 869,715 & 52,061 & $4,966,633$ & $5,959,959$ \\
\hline \multirow[b]{3}{*}{2012} & Büyükbaş & 41,956 & 535,988 & $15,565,089$ & $18,678,106$ \\
\hline & Küçükbaş & 117,350 & 85,666 & $9,251,874$ & $11,102,249$ \\
\hline & Kanatlı & $1,108,221$ & 66,338 & $6,328,656$ & $7,594,387$ \\
\hline \multirow[b]{3}{*}{2013} & Büyükbaş & 42,240 & 539,616 & $15,670,449$ & $18,804,538$ \\
\hline & Küçükbaş & 120,280 & 87,804 & $9,482,875$ & $11,379,450$ \\
\hline & Kanatli & $1,249,082$ & 74,770 & $7,133,063$ & $8,559,675$ \\
\hline \multirow[b]{3}{*}{2014} & Büyükbaş & 40,181 & 513,312 & $14,906,589$ & $17,887,906$ \\
\hline & Küçükbaş & 136,363 & 99,545 & $10,750,859$ & $12,901,031$ \\
\hline & Kanatlı & $1,254,876$ & 75,117 & $7,166,150$ & $8,599,380$ \\
\hline \multirow[b]{3}{*}{2015} & Büyükbaş & 39,198 & 500,755 & $14,541,909$ & $17,450,291$ \\
\hline & Küçükbaş & 117,520 & $857,89,6$ & $9,265,277$ & $11,118,332$ \\
\hline & Kanatli & $1,796,283$ & 107,525 & $10,257,933$ & $12,309,519$ \\
\hline \multirow[b]{3}{*}{2016} & Büyükbaș & 32,499 & 415,175 & $1,2056,674$ & $14,468,009$ \\
\hline & Küçükbaş & 126,810 & 92,571 & $9,997,700$ & $11,997,240$ \\
\hline & Kanatlı & $2,179,332$ & 130,455 & $12,445,389$ & $14,934,467$ \\
\hline \multirow[b]{3}{*}{2017} & Büyükbaş & 36,071 & 460,807 & $13,381,836$ & $16,058,203$ \\
\hline & Küçükbaş & 140,137 & 102,300 & $11,048,401$ & $13,258,081$ \\
\hline & Kanatlı & $4,433,499$ & 265,389 & $25,318,135$ & $30,381,761$ \\
\hline
\end{tabular}

Bilecik ili yıllık üretilen biyogaz değerleri kullanılarak elektrik enerjisi eşdeğeri incelenmiştir. Buna ait hesaplamalar Tablo 3'de sunulmuştur. Daha sonra elektrik enerjisi eşdeğerleri Bilecik ili yıllık elektrik tüketimi değerleri ile karşılaştırılmıştır. Bilecik ili yıllık elektrik tüketimi değerleri Türkiye İstatistik Kurumu internet sitesinden alınmıştır [15]. Bilecik ili yıllık toplam elektrik enerjisi eşdeğeri (kWh) ve yıllık elektrik tüketimi $(\mathrm{kWh})$ karşılaştırıldığında yıllık üretilen biyogaz miktarından elde edilen yıllık toplam elektrik enerjisi eşdeğeri $(\mathrm{kWh})$ değerinin yıllık elektrik tüketimini $(\mathrm{kWh})$ karşıladığı görülmektedir. 
Tablo 3. Bilecik ili hayvan miktarının biyogaz ve elektrik enerjisi eşdeğeri

\begin{tabular}{|c|c|c|c|c|c|}
\hline Yıl & Hayvan Cinsi & $\begin{array}{c}\text { Yıllık } \\
\text { üretilen } \\
\text { biyogaz } \\
(\mathbf{m 3}) \\
\end{array}$ & Elektrik enerjisi eşdeğeri (kWh) & $\begin{array}{l}\text { Yıllık toplam } \\
\text { elektrik enerjisi } \\
\text { eşdeğeri (kWh) }\end{array}$ & $\begin{array}{c}\text { Yıllık Bilecik ili elektrik tüketimi } \\
\text { (kWh) }\end{array}$ \\
\hline \multirow{3}{*}{2011} & Büyükbaş & $17,966,704$ & $84,443,509$ & \multirow{3}{*}{$160,233,331$} & \multirow{3}{*}{$1,284,686,000$} \\
\hline & Küçükbaş & $10,165,535$ & $47,778,015$ & & \\
\hline & Kanatlı & $5,959,959$ & $28,011,807$ & & \\
\hline \multirow{3}{*}{2012} & Büyükbaş & $18,678,106$ & $87,787,098$ & \multirow{3}{*}{$175,661,287$} & \multirow{3}{*}{$1,196,465,000$} \\
\hline & Küçükbaş & $11,102,249$ & $52,180,570$ & & \\
\hline & Kanatlı & $7,594,387$ & $35,693,619$ & & \\
\hline \multirow{3}{*}{2013} & Büyükbaş & $18,804,538$ & $88,381,329$ & \multirow{3}{*}{$182,095,216$} & \multirow{3}{*}{$127,446,000$} \\
\hline & Küçükbaş & $11,379,450$ & $53,483,415$ & & \\
\hline & Kanatlı & $8,559,675$ & $40,230,473$ & & \\
\hline \multirow{3}{*}{2014} & Büyükbaş & $17,887,906$ & $84,073,158$ & \multirow{3}{*}{$185,125,090$} & \multirow{3}{*}{$1,371,199,000$} \\
\hline & Küçükbaş & $12,901,031$ & $60,634,846$ & & \\
\hline & Kanatlı & $8,599,380$ & $40,417,086$ & & \\
\hline \multirow{3}{*}{2015} & Büyükbaş & $17,450,291$ & $82,016,368$ & \multirow{3}{*}{$192,127,267$} & \multirow{3}{*}{$1,514,417,000$} \\
\hline & Küçükbaş & $11,118,332$ & $52,256,160$ & & \\
\hline & Kanatlı & $12,309,519$ & $57,854,739$ & & \\
\hline \multirow{3}{*}{2016} & Büyükbaş & $14,468,009$ & $67,999,642$ & \multirow{3}{*}{$194,578,665$} & \multirow{3}{*}{$1,487,989,000$} \\
\hline & Küçükbaş & $11,997,240$ & $56,387,028$ & & \\
\hline & Kanatlı & $14,934,467$ & $70,191,995$ & & \\
\hline \multirow{3}{*}{2017} & Büyükbaş & $16,058,203$ & $75,473,554$ & \multirow{3}{*}{$280,580,812$} & \multirow{3}{*}{$184,287,000$} \\
\hline & Küçükbaş & $13,258,081$ & $62,312,981$ & & \\
\hline & Kanatlı & $30,381,761$ & $142,794,277$ & & \\
\hline
\end{tabular}

\section{SONUÇLAR}

Bu çalışmada 2011-2017 yılları arasındaki Bilecik ilindeki hayvan (büyükbaş, küçükbaş ve kanatlı) atıkları kullanılarak, biyogaz potansiyeli ve elektrik enerjisi eşdeğeri incelenmiştir. Buna göre biyogaz potansiyelinin en az olduğu y1l 2011, en fazla olduğu yll ise 2017 olarak belirlenmiştir. Biyogaz potansiyel miktarından elde edilebilecek y1llık toplam elektrik enerjisi eşdeğeri ise en fazla 2017 y1lında 280,580,812 olarak hesaplanmıştır $(\mathrm{kWh})$. Bilecik ili yıllık toplam elektrik enerjisi eşdeğeri $(\mathrm{kWh})$ ve yıllık elektrik tüketimi $(\mathrm{kWh})$ karşılaştıııldığında ise yıllık toplam elektrik enerjisi eşdeğeri $(\mathrm{kWh})$ değerinin, yıllık elektrik tüketimini $(\mathrm{kWh})$ karşıladığı görülmektedir.

Hayvan cinsi açısından biyogaz potansiyeli incelendiğinde ise son yıllarda kanatlı hayvan sayısında ve buna bağlı olarak biyogaz potansiyeli ve elde edilebilecek elektrik enerjisi gelir miktarında ciddi bir artış olduğu görülmektedir.

Sonuç olarak, önemli bir hayvancilık potansiyeline sahip Bilecik ilinde, özellikle köylerde yaşayan vatandaşların biyogaz potansiyeli konusunda bilinçlendirilmesi büyük önem taşımaktadır. Çünkü bu konuda köylü vatandaşların bilinçlenmesinin hem köylerde temiz bir ortam sağlayacağı hem de bilinçsiz olarak tezek yakılmasının önüne geçerek büyük bir potansiyelin yok olmasının engelleneceği düşünülmektedir.

\section{KAYNAKLAR}

[1] Hammad M., Badarneh D. \& Tahboub K. (1999). Evaulating variable organic waste to produce methane. Energy Conversion and Management, 40, 1463-1475. 
[2] Doruk, İ., \& Bozdeveci, A. (2017). Denizli ilinin kırsal kesimlerinde hayvansal kaynaklı atıklardan biyogaz potansiyelinin belirlenmesi. Iğdır Üniversitesi Fen Bilimleri Enstitüsü Dergisi, 7(3), 181-186.

[3] Korkmaz, Y., Aykanat, S., \& Çil, A. (2012). Organik Atıklardan biyogaz ve enerji üretimi. SAÜ Fen Edebiyat Dergisi, 1, 489-497.

[4] Çağlayan, G. \& Koçer, N. (2014). Muş ilinde hayvan potansiyelinin değerlendirilerek biyogaz üretiminin araştırılması. Muş Alparslan Üniversitesi Fen Bilimleri Dergisi, 2(1), 215-220.

[5] Diya'uddeen, B.H., Daud, W.M.A.W. \& Aziz A.R.A. (2011). Treatment Technologies for Petroleum Refinery Effluents: A Review. Process Safety and Environmental Protection, 89, 95-105.

[6] Şenol, H., Elibol, E. A., Açıkel, Ü. \& Şenol, M. (2017). Biyogaz üretimi için Ankara’nın başlıca organik atık kaynakları. Bitlis Eren Üniversitesi Fen Bilimleri Dergisi, 6(2), 15-28.

[7] Çanka Kılıç, F. (2011). Biyogaz, Önemi, Genel Durumu ve Türkiye'deki Yeri. Mühendis ve Makina, 52 (617), 94-106.

[8] Ergün, A. \& Çoldan, İ. (2004). Yemler Yem Hijyeni ve Teknolojisi. Ankara Üniversitesi Yayınları, Ankara, 204-207.

[9] Oerther, D.B. (2006). Anaerobic Treatment in the 21st Century, Water Environment Research, 1- 450.

[10] Hande, T. Ü. R. K., Koçer, N. N. \& Hanay, Ö. K. (2015). Elazı̆̆ İli'nde Faaliyet Gösteren Tavuk Çiftliklerindeki Atıklardan Elde Edilebilecek Enerji Potansiyelinin Değerlendirilmesi. Fırat Üniversitesi Mühendislik Bilimleri Dergisi, 27(1), 1-7.

[11] Akbulut, A., Kose, R., \& Akbulut, A. (2014). Technical and economic assessments of biogas production in a family size digester utilizing different feedstock rotations: Döğer case study. International Journal of Green Energy, 11(2), 113-128.

[12] Akdeniz, H. Y. (2015). Çiftlik Tipi Bir Biyogaz Enerji Santralinin Optimizasyonu. Yüksek Lisans Tezi Dumlupınar Üniversitesi, Fen Bilimleri Enstitüsü, Kütahya.

[13] Gül N. (2006). Tavuk Gübresinden Biyogaz Üretim Potansiyelinin Araştırılması. Yüksek Lisans Tezi Süleyman Demirel Üniversitesi, Fen Bilimleri Enstitüsü, Isparta.

[14] Türkiye İstatistik Kurumu (TÜİK), https://biruni.tuik.gov.tr/medas/?kn=101\&locale=tr (Erişim Tarihi: 16/05/2019).

[15] Türkiye İstatistik Kurumu (TÜIK), https://biruni.tuik.gov.tr/bolgeselistatistik/ degiskenlerUzerindenSorgula.do (Erişim Tarihi: 10/06/2019). 